\title{
ADUBAÇÃO NITROGENADA E INCIDÊNCIA DE BRUSONE EM ARROZ DE SEQUEIRO $\left({ }^{1}\right)$
}

\author{
JOSÉ GUILHERME DE FREITAS $\left({ }^{2 *}\right)$; VANDA MARIA ANGELI MALAVOLTA $\left({ }^{2}\right)$; \\ MARCUS VINICIUS SALOMON $\left({ }^{3}\right)$; HEITOR CANTARELLA $\left({ }^{4}\right)$; \\ LÚCIA HELENA SIGNORI MELO DE CASTRO $\left({ }^{2}\right)$; LUIZ ERNESTO AZZINI $\left({ }^{2}\right)$
}

\begin{abstract}
RESUMO
O objetivo deste trabalho foi avaliar a incidência e severidade da brusone em duas cultivares de arroz, em resposta a níveis de adubação nitrogenada. O experimento foi instalado em Mogi Mirim (SP), no ano agrícola 2003/2004, em delineamento de blocos ao acaso com parcelas subdivididas. As parcelas consistiram de doses de nitrogênio em cobertura $\left(0,50,100\right.$ e $150 \mathrm{~kg}^{-1}$ ha e a subparcela em duas cultivares de arroz (IAC 201 e IAC 202). Foi empregada adubação de semeadura de $400 \mathrm{~kg}^{-1}$ de 0-14-08 de NPK acrescido de $1 \%$ de $\mathrm{Zn}$ e $0,5 \%$ de $\mathrm{B}$, em todos os tratamentos. Intensa ocorrência de brusone, causada pelo fungo Pyricularia grisea, foi observada no experimento. Em condições de campo foram avaliadas a severidade de brusone nas panículas e a produtividade de grãos; em laboratório, a incidência de $P$. grisea nas panículas e nas sementes, a massa de mil grãos, o rendimento de grãos inteiros e quebrados, e a porcentagem de espiguetas estéreis. A incidência de $P$. grisea nas sementes e a severidade da doença nas panículas foram maiores nas parcelas que receberam $\mathrm{N}$ em cobertura em relação àquelas sem este nutriente, e foram maiores na cultivar IAC 202 que na IAC 201 para as condições deste experimento. A adubação nitrogenada de cobertura também provocou aumento na porcentagem de espiguetas estéreis e na porcentagem de grãos quebrados e causou redução de $22 \%$ na produtividade de grãos em casca. Correlação linear positiva foi obtida entre severidade de brusone nas panículas e incidência de P. grisea nas sementes. Os resultados do presente trabalho evidenciam a necessidade do uso de fungicidas quando se utiliza adubação nitrogenada em cultivares de arroz suscetíveis a brusone.
\end{abstract}

Palavras-chave: Oryza sativa, nitrogênio, brusone, rendimento de grãos, Pyricularia grisea.

$\left(^{1}\right)$ Recebido para publicação em 20 de agosto de 2008 e aceito em 6 de outubro de 2009.

$\left({ }^{2}\right)$ Centro de Análise e Pesquisa Tecnológica do Agronegócio de Grãos e Fibras, Instituto Agronômico, Caixa Postal 28, 13001-970 Campinas (SP). E-mail: jfreitas@iac.sp.gov.br (*) Autor correspondente.

$\left({ }^{3}\right)$ Pós-graduando em Engenharia Agrícola, UNICAMP,Campinas (SP).

$\left({ }^{4}\right)$ Centro de Pesquisa e Desenvolvimento de Solos e Recursos Ambientais, Instituto Agronômico, Caixa Postal 28, 13001-970 Campinas (SP). 


\title{
ABSTRACT \\ NITROGEN FERTILIZATION AND BLAST INCIDENCE IN UPLAND RICE
}

\begin{abstract}
A field experiment was set up in Mogi Mirim, SP, in 2003/2004 to study the effect of N fertilizer on the incidence of rice blast, caused by Pyricularia grisea in two rice cultivars. The experimental design was a split-plot in randomized blocks with 4 replications. Rates of $\mathrm{N}$ sidedressed 40 days after seed germination $\left(0,50,100\right.$, and $\left.150 \mathrm{~kg} \mathrm{ha}^{-1} \mathrm{~N}\right)$ were placed in the plots and rice cultivars (IAC 201 and IAC 202) in the subplots. Fertilization common to all treatments was applied in the seed furrow comprising 16, 56, and $32 \mathrm{~kg} \mathrm{ha}^{-1}$ of $\mathrm{N}, \mathrm{P}_{2} \mathrm{O}_{5}$, and $\mathrm{K}_{2} \mathrm{O}$, respectively. An intense incidence of blast was observed. Rice plants were evaluated for severity of disease in panicles (using a grading system) and in seeds (by the blotter test), sterile spiklets, grain density and yield, and percentage of broken grain. The incidence of rice blast in seeds as well as the panicle blast disease severity were significantly higher in plants fertilized with N and were also higher for IAC 202 than for IAC 201. However, IAC 201 could not be considered resistant/ tolerant do P. grisea. A highly significant linear correlation coefficient was observed between incidence of $P$. grisea in seeds and disease severity in panicle. Grain yield was negatively correlated with blast incidence and severity, and with the percentage of sterile spiklets. Therefore, sidedressed $\mathrm{N}$ fertilization increased seed damage caused by $P$. grisea, the percentage of sterile spiklets, and the percentage of broken grains, thereby causing a decrease in rice yield (22\% lower at the higher $\mathrm{N}$ rate) and grain density. The results of the present study suggest that the use of fungicides is necessary when rice cultivars susceptible to blast are fertilized with nitrogen.
\end{abstract}

Key words: Oryza sativa, nitrogen, blast, grains yield, Pyricularia grisea.

\section{INTRODUÇÃO}

No cultivo de arroz de sequeiro pode haver alta produtividade de grãos, desde que ocorra boa quantidade e distribuição de chuvas ou irrigação por aspersão, aplicação adequada de nutrientes, em particular o nitrogênio $(\mathrm{N})$, uso de cultivares melhoradas para aquelas condições, tratos culturais adequados e controle de doenças, principalmente da brusone.

$\mathrm{O}$ arroz de sequeiro pode ser responsivo e eficiente ao $\mathrm{N}$, desde que outros fatores que limitam o uso desse nutriente não estejam presentes. ARF et al. (2000), estudando arroz de terras altas irrigado por aspersão com pivô central, utilizando $100 \mathrm{~kg} \mathrm{ha}^{-1}$ de $\mathrm{N}$ obtiveram boas produtividades de grãos em casca em alguns genótipos, entre eles o IAC $201(5.571 \mathrm{~kg}$ $\left.\mathrm{ha}^{-1}\right)$ e o IAC $202\left(5.046 \mathrm{~kg} \mathrm{ha}^{-1}\right)$.

As cultivares de uma mesma espécie revelam exigências nutricionais e tolerâncias diferenciadas para os estresses de nutrientes, segundo BROwN e JONES (1997); Fageria e Barbosa Filho (1981). O aumento da produtividade de grãos de arroz via maior resposta a esse nutriente foi verificada com diferentes doses de N (ANDRADE et al., 1992; BORRELl et al., 1998). SHARMA e SHARMa (1999), trabalhando com doses crescentes de nitrogênio $\left(2,20,40,60,80,100,120\right.$ e $140 \mathrm{~kg} \mathrm{ha}^{-1}$ de $\mathrm{N})$ em cultivares de arroz, não obtiveram resposta para a cultivar Colombiano durante três anos, enquanto para 'IRGA 416' houve resposta em uma das safras estudadas.

A variabilidade de resposta à aplicação de nitrogênio também foi observada em três cultivares de arroz irrigado por inundação (IAC 101, IAC 102 e IAC 104) com relação ao rendimento de grãos e a alguns componentes de rendimento, situando-se a dose econômica ao redor de $150 \mathrm{~kg} \mathrm{ha}^{-1}$ de $\mathrm{N}$ (Freitas et al., 2001).

Dentre os fatores que condicionam o grau de severidade das doenças, a nutrição mineral das plantas merece especial atenção. De maneira geral, a condição nutricional que permite o máximo crescimento e desenvolvimento da planta também favorece a manifestação de doenças.

$\mathrm{O} N$ tem um importante papel no metabolismo vegetal, pois em caso de deficiência provoca a redução no crescimento e desenvolvimento das plantas, e consequentemente, queda na produtividade e qualidade dos grãos. Em excesso, intensifica o processo vegetativo, podendo interferir, favoravelmente ou não, no desenvolvimento de fungos patogênicos, dependendo do local de ação do patógeno. Normalmente, patógenos foliares são favorecidos por maiores níveis de $\mathrm{N}$, que propiciam maior desenvolvimento e conseqüentemente maior quantidade de tecidos tenros e suculentos. Por outro lado, patógenos de solo podem ser reduzidos, uma vez que plantas mais vigorosas produzem mais raízes que compensam os danos causados pelo patógeno (HUBER e THOMPSON, 2005).

$\mathrm{Na}$ cultura do arroz, relatos mostram que o aumento nos níveis de $\mathrm{N}$ causa maior incidência e/ ou severidade de doenças (LONG et al., 2000; PrABHU et al., 1996; SAntos et al., 1986; Silva et al., 2003). Também para outras doenças do arroz há relatos de 
aumento na sua severidade com o emprego de maiores doses de N, como queima das bainhas, causada por Rhizoctonia solani (SAVARY et al., 1995) e podridão do colmo, causada por Magnaporthe salvinii (HubER e THOMPSON, 2005).

Os objetivos deste trabalho foram: estudar as respostas de duas cultivares de arroz ao nitrogênio e avaliar a relação entre doses de $\mathrm{N}$ e produtividade de grãos em casca, índice de fertilidade das espiguetas, massa de mil grãos, rendimento de grãos e incidência de doenças.

\section{MATERIAL E MÉTODOS}

O experimento foi instalado em 2003/2004, em Mogi Mirim (latitude $22^{\circ} 25^{\prime} 55^{\prime \prime} S$, longitude $\left.46^{\circ} 47^{\prime} 28^{\prime \prime} \mathrm{W}\right)$, com clima subtropical quente e estiagem no inverno, e solo Latossolo Vermelho-Amarelo Distrófico típico, textura argilosa, A moderado, hipodistrófico, álico (EMBRAPA, 1999). As análises químicas de amostras de solo da camada de $0-20 \mathrm{~cm}$ de profundidade (RAIJ et al., 2001) apresentaram os seguintes resultados: M.O. $=35 \mathrm{~g} \mathrm{dm}^{-3} ; \mathrm{pH}=4,9$ $\left(\mathrm{CaCl}_{2}\right) ; \mathrm{P}_{\text {resina }}=7,0 \mathrm{mg} \mathrm{dm}^{-3} ; \mathrm{K}=1,3 \mathrm{mmol}_{\mathrm{c}} \mathrm{dm}^{-3}$; $\mathrm{Ca}=60 \mathrm{mmol}_{\mathrm{c}} \mathrm{dm}^{-3} ; \mathrm{Mg}=30 \mathrm{mmol}_{\mathrm{C}} \mathrm{dm}^{-3} ; \mathrm{H}+\mathrm{Al}=30$ $\mathrm{mmol}_{\mathrm{C}} \mathrm{dm}^{-3} ; \mathrm{CTC}=121 \mathrm{mmol}_{\mathrm{c}} \mathrm{dm}^{-3} \mathrm{e} \mathrm{V}=70 \%$.

$\mathrm{O}$ arroz foi semeado nas unidades experimentais em 19/11/2003 e os experimentos desenvolvidos sob condição de sequeiro, em área mantida sob pousio durante o outono-inverno.

O delineamento estatístico utilizado foi em blocos ao acaso, em esquema de parcelas subdivididas, com quatro repetições. Nas parcelas foram aplicadas quatro doses de nitrogênio $\left(0,50,100\right.$ e $\left.150 \mathrm{~kg} \mathrm{~N} \mathrm{ha}^{-1}\right)$, na forma de uréia, e em cobertura aos 40 dias após a emergência das plântulas de arroz. As subparcelas foram constituídas pelas duas cultivares de arroz, semeadas manualmente em 6 linhas de $5 \mathrm{~m}$ de comprimento, com espaçamento entre linhas de $0,40 \mathrm{~m}$. As cultivares IAC 201 e IAC 202 foram utilizadas por serem recomendadas para semeadura no Estado de São Paulo e terem se destacado nos últimos anos pelo bom potencial produtivo e rendimento de grãos. A cultivar IAC 202 é de porte baixo e ciclo médio e a 'IAC 201', de porte alto e ciclo precoce.A adubação na semeadura, comum a todas as unidades experimentais, foi aplicada na linha de semeadura na dose correspondente a $400 \mathrm{~kg} \mathrm{ha}^{-1}$ da fórmula 04-14-08 de NPK + Zn e B, de acordo com RaIJ et al. (1996).

A quantificação da brusone foi feita avaliando-se a severidade da doença nas panículas, efetuada em condições de campo, avaliando-se 20 panículas coletadas ao acaso no estádio massa, em cada unidade experimental, utilizando-se escala visual de 6 graus: 0 (sadia), 5, 25, 50, 75 e 100\% de porcentagem de área da panícula afetada. A incidência de brusone nas sementes foi avaliada através de análise sanitária, utilizando-se o método do papel de filtro com congelamento (MARA, 1992), em amostras constituídas por 200 sementes procedentes das unidades experimentais no campo, após a colheita e abanação.

Quatro linhas centrais de cada unidade experimental foram colhidas para avaliação do rendimento de grãos em casca. Por ocasião da colheita, coletaram-se 10 panículas ao acaso, por unidade experimental, e avaliaram-se os comprimentos da panícula e os componentes do rendimento de grãos (número de espiguetas por panícula, fertilidade das espiguetas e massa de mil grãos). A renda no benefício e a porcentagem de grãos inteiros foram estimadas a partir do beneficiamento de amostra de $100 \mathrm{~g}$ de arroz em casca por unidade experimental, em engenho de prova, modelo MT-97 No 2598-5, Fabricante Indústrias Suzuki S.A., em Santa Cruz do Rio Pardo (SP). A renda no benefício foi expressa pelo percentual total de arroz beneficiado (grãos inteiros, quebrados e quirera), e o rendimento de grãos expresso pelo percentual de inteiros. $\mathrm{O}$ índice de fertilidade das espiguetas foi determinado dividindo-se o número de espiguetas cheias pelo número total de espiguetas por panícula e multiplicando-se por 100.

Foram realizadas as análises da variância individuais para as características estudadas, com auxílio do programa Sistema de Análise Estatística SANEST (ZONTA et al., 1987). Empregou-se o teste de Tukey, ao nível de 5\%, para comparar as médias entre cultivares, conforme Cochran e Cox (1957). O teste F a $5 \%$ de probabilidade foi utilizado para avaliar a significância das equações polinomiais referentes aos efeitos de nitrogênio aplicado. Foram realizadas análises de correlação linear simples (ao nível de 5\% de probabilidade, pelo teste $\mathrm{t}$ ), para estimar as relações entre produtividade de grãos em casca, severidade de doenças, índice de fertilidade das espiguetas, massa de mil grãos, porcentagem de espiguetas estéreis, porcentagem de grãos quebrados e rendimento de grãos.

\section{RESULTADOS E DISCUSSÃO}

A cultivar IAC 201 teve maior produtividade de grãos em casca do que a IAC 202 (Tabela 1). Esse resultado deve-se certamente à maior incidência de brusone na cv. IAC 202 (Tabela 2) e não ao potencial produtivo das cultivares, pois em condições desfavoráveis à ocorrência de doenças, a produtividade da IAC 202 é ligeiramente maior que da IAC 201, conforme resultados de 60 experimentos realizados durante o desenvolvimento dessas cultivares (IAC, 1998). 
Tabela 1. Produtividade de grãos de duas cultivares de arroz de sequeiro, em resposta a doses de nitrogênio. Área sem aplicação de fungicida para controle de brusone

\begin{tabular}{|c|c|c|c|c|c|c|c|}
\hline \multirow{2}{*}{ Cultivar } & \multicolumn{4}{|c|}{ Dose de nitrogênio } & \multirow{2}{*}{ Média } & \multirow{2}{*}{ Resposta ao N $\left({ }^{1}\right)$} & \multirow{2}{*}{$\mathrm{R} 2$} \\
\hline & 0 & 50 & 100 & 150 & & & \\
\hline & 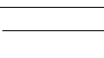 & $\bar{z}$ & & 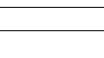 & & & \\
\hline IAC 201 & 3.483 & 3.570 & 3.070 & 2.641 & $3.191 \mathrm{a}$ & ns & - \\
\hline IAC 202 & 3.274 & 3.000 & 2.570 & 2.599 & $2.861 \mathrm{~b}$ & ns & - \\
\hline Média & 3.378 & 3.285 & 2.820 & 2.620 & - & $\mathrm{L}$ & 0,94 \\
\hline
\end{tabular}

Médias seguidas da mesma letra na coluna, não diferem significativamente (Tukey, $5 \%$ ). C.V. $(\%)=9,2$

$\left({ }^{1}\right)$ Regressões polinomiais, L. efeito linear significativo $(\mathrm{P}<0,5)$.

Tabela 2. Severidade na panícula (nota de 1 a 5) e incidência de brusone (\%) nas sementes de cultivares de arroz de sequeiro, em resposta às doses de nitrogênio. Área sem aplicação de fungicida para controle de brusone

\begin{tabular}{|c|c|c|c|c|c|c|c|}
\hline \multirow{2}{*}{ Cultivar } & \multicolumn{4}{|c|}{ Dose de nitrogênio $\left(\mathrm{kg} \mathrm{ha}^{-1}\right)$} & \multirow{2}{*}{ Média } & \multirow{2}{*}{ Resposta a N $\left({ }^{1}\right)$} & \multirow{2}{*}{$\mathrm{R}^{2}$} \\
\hline & 0 & 50 & 100 & 150 & & & \\
\hline & \multicolumn{4}{|c|}{ Severidade de brusone (nota 0 a 5 ) } & & & \\
\hline IAC 201 & 1,33 & 3,93 & 3,80 & 3,61 & $3,17 \mathrm{~b}$ & ns & - \\
\hline IAC 202 & 3,20 & 4,10 & 3,97 & 4,45 & 3,93 a & ns & - \\
\hline \multirow[t]{2}{*}{ Média } & 2,26 & 4,02 & 3,88 & 4,03 & - & Q & 0,89 \\
\hline & \multicolumn{4}{|c|}{ Incidência de brusone $(\%)$} & & & \\
\hline IAC 201 & 36,9 & 46,7 & 48,1 & 48,2 & $44,9 \mathrm{~b}$ & ns & - \\
\hline IAC 202 & 49,3 & 55,7 & 52,2 & 57,6 & $53,6 \mathrm{a}$ & ns & - \\
\hline Média & 46,2 & 51,2 & 50,6 & 52,9 & - & ns & - \\
\hline
\end{tabular}

Coeficientes de variação: $11 \%$ para severidade e $36 \%$ para intensidade de brusone.

Médias seguidas da mesma letra na coluna, não diferem significativamente (Tukey, 5 \%).

$\left({ }^{1}\right)$ Regressões polinomiais. $Q=$ efeito quadrático significativo $\mathrm{P}<0,05$.

Um dos motivos que levou à maior incidência de brusone na cv. IAC 202 foi, provavelmente, o ciclo mais longo, que permitiu a exposição das plantas ao patógeno por mais tempo.

Neste trabalho, a produtividade média de grãos em casca das cultivares IAC 201 e IAC 202 foi, respectivamente, 3.191 e $2.861 \mathrm{~kg} \mathrm{ha}^{-1}$, inferiores às observadas por ARF et al. (2000), com as mesmas cultivares (acima de $5 \mathrm{t} \mathrm{ha}^{-1}$ ), porém na ausência de doença.

$\mathrm{O}$ aumento na dose do $\mathrm{N}$ provocou efeito linear negativo sobre a produtividade de grãos em casca (Tabela 1), observando-se queda de $22 \%$ na produtividade média do tratamento com maior dose $\left(150 \mathrm{~kg} \mathrm{ha}^{-1}\right.$ de N) em relação à testemunha sem $\mathrm{N}$, em decorrência da maior severidade de brusone. Decréscimo na produtividade em função do aumento de doses de $\mathrm{N}$, com consequente aumento de incidência de brusone, foi relatado em experimento realizado com a cultivar IAC 47 por SANTOS et al. (1986). Esses autores observaram queda de até $50 \%$ na produtividade de grãos em casca. Fica evidente a necessidade de controle químico da brusone, ao se utilizar adubação com $\mathrm{N}$ em cultivares suscetíveis à doença, confirmando resultados obtidos anteriormente por FAgeria e PRABHU (2004), que relataram aumento na produção de grãos de arroz da cultivar Metica 1 com a aplicação de altas doses de $\mathrm{N}\left(100\right.$ a $\left.160 \mathrm{~kg} \mathrm{ha}^{-1}\right)$ e simultânea aplicação de fungicida. Na ausência de déficit hídrico e doenças, principalmente brusone, vários trabalhos tiveram alta resposta da produtividade de arroz à adubação nitrogenada, tanto em condições de irrigação por inundação como em cultivo de terras altas com irrigação por aspersão (ARF et al., 2000; FREITAS et al., 2001)

Conforme discutido anteriormente, a 'IAC 202' tem um ciclo mais longo do que a 'IAC 201', podendo ser essa uma das causas da maior incidência de brusone. A severidade da doença aumentou de forma quadrática em função do aumento das doses de $\mathrm{N}$ (Tabela 2). Na dose de $50 \mathrm{~kg} \mathrm{ha}^{-1}$ de $\mathrm{N}$, o índice de severidade da brusone atingiu valores semelhantes aos das doses de 100 e $150 \mathrm{~kg} \mathrm{ha}^{-1}$ de N. Em trabalho 
realizado por Fillipi e PrabHu (1998), com quatro cultivares de arroz de sequeiro, também se observou relação quadrática entre severidade da doença e concentração de $\mathrm{N}$ nos tecidos.

Os resultados da incidência do fungo $P$. grisea nas sementes foram altamente correlacionados ao da severidade da brusone na panícula (Tabela 2). $\mathrm{Na}$ cultivar IAC 202, houve incidências maiores do que na 'IAC 201'. Porém, a incidência de brusone nas sementes não foi afetada pelas doses de $\mathrm{N}$, atingindo valores de quase $50 \%$, mesmo nas parcelas sem a aplicação deste nutriente.

Na cultivar IAC 202, ocorreu maior índice de esterilidade das espiguetas diferindo estatisticamente da 'IAC 201' (Tabela 3). Esse resultado foi semelhante ao obtido para severidade de brusone na panícula e incidência do fungo na semente. A resposta do índice de esterilidade das espiguetas à aplicação do $\mathrm{N}$ foi linear e devida à ocorrência de brusone, com aumento médio de $68 \%$ no número de espiguetas estéreis, considerandose a menor e maior dose de $\mathrm{N}$ respectivamente. Esse resultado confirma os dados obtidos por SANTOS et al. (1986), que observaram redução de até $67 \%$ no número de grãos cheios por panícula, conforme se aumentava a dose de $\mathrm{N}$ e, consequentemente, a incidência de brusone.

A massa de mil grãos da 'IAC 202' foi significativamente maior que da 'IAC 201' (Tabela 3), revelando resposta linear negativa com aplicação do N (Tabela 3), sendo a redução média das duas cultivares de 8,7\%. Esse efeito decrescente e linear da massa de grãos de arroz foi também observado por SANTOS et al. (1986), que relataram redução de aproximadamente $15 \%$, conforme se aumentou a dose de $\mathrm{N}$ de 0 para $60 \mathrm{~kg}$ ha. ${ }^{-1}$.

Não houve diferença significativa entre as duas cultivares para a porcentagem de grãos inteiros, mas sim resposta linear negativa significativa da média das duas cultivares à adubação nitrogenada (Tabela 3). Nesse caso, o aumento das doses de $\mathrm{N}$ acarretou diminuição na porcentagem de grãos inteiros devido à maior incidência de brusone. $\mathrm{Na}$ cultivar IAC 202, a porcentagem de grãos quebrados foi significativamente inferior à da 'IAC 201' mesmo tendo sido mais infectada pela doença (Tabela 3). As respostas da porcentagem de grãos quebrados das duas cultivares revelaram efeito quadrático negativo ao $\mathrm{N}$, mas na média entre as duas cultivares o efeito foi linear (Tabela 3).

Tabela 3. Componentes de produção de cultivares de arroz de sequeiro, em resposta a doses de nitrogênio. Área sem aplicação de fungicida para controle de brusone

\begin{tabular}{|c|c|c|c|c|c|c|c|}
\hline \multirow{2}{*}{ Cultivar } & \multicolumn{4}{|c|}{ Dose de nitrogênio $\left(\mathrm{kg} \mathrm{ha}^{-1}\right)$} & \multirow{2}{*}{ Média } & \multirow{2}{*}{ Efeitos $\left({ }^{1}\right)$} & \multirow{2}{*}{$\mathrm{R}^{2}$} \\
\hline & 0 & 50 & 100 & 150 & & & \\
\hline & \multicolumn{7}{|c|}{ I Índice de esterilidade de espigueta $(\%)$} \\
\hline IAC 201 & 22,3 & 25,3 & 66,5 & 56,5 & $42,6 \mathrm{~b}$ & ns & \\
\hline IAC 202 & 59,5 & 49,3 & 67,5 & 81,3 & $64,4 \mathrm{a}$ & ns & \\
\hline \multirow[t]{2}{*}{ Média } & 40,9 & 37,3 & 67,0 & 68,9 & & $\mathrm{~L}$ & 0,77 \\
\hline & \multicolumn{7}{|c|}{ Grãos inteiros $(\%)$} \\
\hline IAC 201 & 64 & 56 & 46 & 57 & 56 a & ns & \\
\hline IAC 202 & 67 & 57 & 64 & 47 & 59 a & ns & \\
\hline \multirow[t]{2}{*}{ Média } & 66 & 57 & 55 & 52 & & $\mathrm{~L}$ & 0,88 \\
\hline & \multicolumn{7}{|c|}{ Massa de mil grãos $(\mathrm{g})$} \\
\hline IAC 201 & 25,0 & 23,3 & 21,5 & 21,6 & $22,8 \mathrm{~b}$ & ns & \\
\hline IAC 202 & 25,7 & 25,7 & 25,0 & 24,6 & $25,3 \mathrm{a}$ & ns & \\
\hline \multirow[t]{2}{*}{ Média } & 25,3 & 24,5 & 23,2 & 23,1 & & $\mathrm{~L}$ & 0,93 \\
\hline & \multicolumn{7}{|c|}{ Grãos quebrados $(\%)$} \\
\hline IAC 201 & $12 \mathrm{a}$ & 15 a & $26 \mathrm{a}$ & $22 \mathrm{a}$ & 19 a & Q & 0,77 \\
\hline IAC 202 & $14 \mathrm{a}$ & $13 \mathrm{a}$ & $12 \mathrm{~b}$ & $24 \mathrm{a}$ & $16 \mathrm{~b}$ & Q & 0,90 \\
\hline Média & 13 & 14 & 19 & 23 & & $\mathrm{~L}$ & 0,95 \\
\hline
\end{tabular}

Coeficientes de variação: 34 \% (índice de esterilidade); 4 (massa de mil grãos); 12\% (grãos inteiros); 11\% (grãos quebrados).

Médias seguidas da mesma letra na coluna, não diferem significativamente (Tukey, 5 \%).

$\left({ }^{1}\right)$ Regressões polinomiais. $\mathrm{Q}=$ efeito quadrático significativo $\mathrm{P}<0.05$. 
Estes resultados podem ser explicados pela utilização pelo fungo de parte dos produtos elaborados pela planta, os quais deveriam ser totalmente armazenados nos drenos (grãos).

A produtividade de grãos em casca e a porcentagem de grãos inteiros tiveram correlações negativas em relação à severidade da brusone e à porcentagem de espiguetas estéreis (Tabela 4). A porcentagem de grãos quebrados correlacionouse negativamente com a porcentagem de grãos inteiros e positivamente com a porcentagem de espiguetas estéreis; a massa de mil grãos, significativa e positivamente com a porcentagem de grãos inteiros e negativamente com a porcentagem de grãos quebrados (Tabela 4). Esses resultados concordam com os obtidos anteriormente por SANTOS et al. (1986), em estudos desenvolvidos com a cultivar IAC 47, considerando os parâmetros produtividade e massa de grãos, esterilidade e grãos cheios, e também com PrabHu et al. (1996) com relação aos parâmetros peso e produtividade de grãos.

Tabela 4. Correlação entre severidade de brusone (BRU), produtividade de grãos (PRO), porcentagem de grãos inteiros (PGI), porcentagem de grãos quebrados (GQ), porcentagem de espiguetas estéreis $(\mathrm{CH})$ e massa de mil grãos (MMG), de cultivares de arroz de sequeiro. Área sem aplicação de fungicida para controle de brusone

\begin{tabular}{lccccc}
\hline Característica & BRU & PRO & PGI & $\% G Q$ & $\% \mathrm{CH}$ \\
\hline PRO & $-0,463^{*}$ & - & - & - & - \\
PGI & $-0,466^{*}$ & 0,166 & - & - & - \\
\%GQ & 0,311 & $-0,299$ & $-0,717^{*}$ & - & - \\
\%CH & 0,340 & $-0,536^{*}$ & $-0,234$ & $0,439^{*}$ & - \\
MMG & $-0,152$ & 0,067 & $0,412^{*}$ & $-0,568^{*}$ & 0,069 \\
\hline
\end{tabular}

* Significativo pelo teste t a $5 \%=0,39$

Foi relatado anteriormente que a resistência parcial ou de campo presente nas cultivares melhoradas de arroz de sequeiro é influenciada por níveis de nitrogênio empregados na adubação, sendo essa resistência expressa somente sob níveis baixos de N (Prabhu et al., 1996). No presente trabalho, a incidência da doença foi pouco afetada pela dose de $\mathrm{N}$, apesar da severidade de brusone ter sido menor nas parcelas sem $\mathrm{N}$, especialmente para a cultivar IAC 201.

Os resultados deste trabalho reforçam que para obtenção de alta produtividade de arroz de sequeiro é necessário o emprego de adubação nitrogenada aliada à utilização de controle químico da brusone. Esses resultados são consistentes com outros estudos que mostraram a ação benéfica do nitrogênio quando associado à adoção de medidas de controle químico (FAgEria e PrabHU, 2004; LONG et al., 2000; SiLVA et al., 2003).

Como a ocorrência de brusone é extremamente dependente da prevalência de condições climáticas favoráveis ao desenvolvimento do patógeno, e considerando que sob tais condições a evolução epidêmica da doença é muito rápida, fica evidente a necessidade do controle químico preventivo durante a fase de emergência de panículas. Esse período é limitado a poucos dias, e nesse estádio a adoção de medidas de controle químico é decisiva para o efetivo controle da doença, uma vez que, após ocorrida a infecção, medidas curativas são pouco eficientes.

\section{CONCLUSÕES}

1. O aumento das doses de nitrogênio provoca maior severidade de brusone nas panículas e incidência do patógeno nas sementes, em condições de campo.

2. As cultivares de arroz são diferentemente responsivas à adubação nitrogenada quanto à suscetibilidade a brusone.

3. O esperado aumento no benefício na produtividade de grãos após adubação nitrogenada é prejudicado pela maior severidade de brusone nas panículas, decorrente dessa adubação.

\section{REFERÊNCIAS}

ARF, O.; RODRIGUES, R.A.F.; SÁ M.E.; CRUCIOL, C. A.C. Influência da época de semeadura no comportamento de cultivares de arroz irrigado por aspersão em Selvíria, MS. Pesquisa Agropecuária Brasileira, v.35, p.1967-1976, 2000.

ANDRADE, W.E.B.; AMORIM NETO, S.; FERNANDES, G.M.B.; OLIVEIRA, H.F. Épocas de aplicação de nitrogênio em cultivares de arroz irrigado na Região Norte Fluminense. Lavoura Arrozeira, v.45, p.14-17, 1992.

BORRELL, A.K.; GARSIDE, A.L.; FUKAI, S.; REID, D.J. Season and plant type affect the response of rice yield to nitrogen fertilization in a semi-arid tropical environment. Australian Journal of Agricultural Research, v.49, p.179-190, 1998.

BROWN, J.C.; JONES, W.E. Fitting plant nutritionally to soil. I. Soybeans. Agronomy Journal, v.69, p.399-404, 1997.

COCHRAN, W.G; COX, G.M. Experimental designs. 2.ed. New York: John Wiley \& Sons, 1957. 
EMBRAPA. Centro Nacional de Pesquisa de Solos. Sistema brasileiro de classificação de solos. Brasília: Embrapa Produção de Informação; Rio de Janeiro: Embrapa Solos, 1999. 412p.

FAGERIA, N.K.; BARBOSA FILHO, M.P. Avaliação de cultivares de arroz para a maior eficiência de absorção de fósforo. Pesquisa Agropecuária Brasileira, v.16, p.772$782,1981$.

FAGERIA, N.K.; PRABHU, A.S. Controle de brusone e manejo de nitrogênio em cultivo de aroz irrigado. Pesquisa Agropecuária Brasileira, v.39, p.123-129, 2004

FILLIPI, M. C.; PRABHU. A S. Relationship between panicle blast severity and mineral nutrient content of plant tissue in upland rice. Journal of Plant Nutrition, v.21, p.1577-1587, 1998

FREITAS, J.G.; AZZINI, L.E.; CANTARELLA, H.; BASTOS, C.R.; CASTRO, L.H.S.M. de; GALLO, P.B.; FELÍCIO, J.C. Resposta de cultivares de arroz irrigado ao nitrogênio. Scientia Agrícola, v.58, p.573-579, 2001.

HUBER, D.M.; THOMPSON; I.A. Nitrogen and plant disease. In: SIMPÓSIO SOBRE RELAÇÕES ENTRE NUTRIÇÃO MINERAL E INCIDÊNCIA DE DOENÇAS DE PLANTAS, 2005, Piracicaba. Resumos... Piracicaba: Potafós, 2005.

INSTITUTO AGRONÔMICO - IAC. IAC 202 - Arroz de sequeiro para o Estado de São Paulo. Campinas, 1998. 6p. (Fôlder)

LONG, D.H.; LEE, F.N.; TEBEEST, D.O. Effect of nitrogen fertilization on disease progress of rice blast on susceptible and resistant cultivars. Plant Disease, v.84, p.403-409, 2000.

MARA - Ministério da Agricultura e Reforma Agrária. Teste de sanidade de sementes. In: Regras para Análise de Sementes. Brasília, 1992. p.204-212.

PRABHU, A.S.; FILIPPI, M.C.; ZIMMERMANN, F.J.P. Genetic control of blast in relation to nitrogen fertilization in upland rice. Pesquisa Agropecuária Brasileira, v.31, p.339-347, 1996.

SANTOS, A.B.; PRABHU, A.S.; AQUINO, A.R.L.; CARVALHO, J.R.P. Épocas, modos de aplicação e níveis de nitrogênio sobre brusone e produção de arroz de sequeiro. Pesquisa Agropecuária Brasileira. v.21, p.697-707, 1986.

SAVARY, S.; CASTILLA, N.P.; ELAZEGUI, F.A.; MCLAREN, C.G.; YNALVEZ, M.A.; TENG, P.S. Direct and indirect effects of nitrogen supply and disease sources structures on rice sheath blight spread. Phytopathology, v.85, p.959-965, 1995.

SHARMA, D.K.; SHARMA, D.R. Sustainable use of poor quality water with proper scheduling of irrigation and nitrogen levels for a rice crop. Water Science and Tecnology. v.40, p.111-114, 1999.

SILVA, G.B.; PRABHU,A.S. ;ZIMMERMANN, F.J.P. Manejo integrado da brusone em arroz no plantio direto e convencional. Pesquisa Agropecuária Brasileira, v.38, p.481487, 2003.
RAIJ, B. van; CANTARELLA, H.; QUAGGIO, J.A.; FURLANI, A.M.C. Recomendações de adubação e calagem para o Estado de São Paulo. 2.ed. Campinas: Instituto Agronômico/ Fundação IAC, 1996. 285p. (Boletim Técnico, 100)

RAIJ, B. van; ANDRADE. J.C. de CANTARELLA, H.; QUAGGIO, J.A. Análise química para avaliação da fertilidade de solos tropicais. Campinas, Instituto Agronômico, 2001. 285p.

ZONTA, E.P.; MACHADO, A.A.; SILVEIRA JUNIOR, P. Sistema de análise estatística para microcomputadores: manual de utilização. 2.ed. Pelotas: UFP, 1987. 177p. 